\title{
How do I improve my time management skills?
}

With a busy schedule, it's important to make the most of your time during the working day. Abi Rimmer talks to four experts about how to do this successfully

\section{Abi Rimmer}

The BMJ

\section{Don't neglect self care}

Laura-Jane Smith, consultant in respiratory and internal medicine at King's College London, says, "In the clinical environment it may feel like you have little control over your time but there are things you can do. Successful prioritisation is a skill that you can develop, and batching related tasks can also help. If you need to concentrate, mute your phone and ask a colleague to hold your bleep. If you're always leaving late, tracking your time using a diary or an app like Clockify can help you understand how you could work smarter.

"For career progression, identify what you most want to achieve and write it down. You don't need grand aims-just set goals that are meaningful to you and be realistic about what steps are needed to achieve them. Give yourself deadlines and discuss progress with a mentor or supervisor.

"If you feel unable to manage your time, take a critical look at whether the problem is you or your environment. Colleagues or family may be asking too much of you and you may need to say no. Sometimes telling someone about your other commitments is enough. Sometimes you need to be more direct. If your boss keeps asking for more, ask which existing tasks can be deferred, in order to prioritise the new.

"Most importantly, take time for yourself. Decision fatigue has potentially serious consequences. Walk the outside route between wards to get some fresh air. Make plans outside work and keep them. Commit to spending time on things that bring you professional satisfaction and personal joy. Self care is not a luxury, it's a responsibility."

\section{Follow five principles}

Trevor Bibic, learning and development consultant at Brightbloom Training, says, "Start with the basics.

"Get it out of your head-trying to juggle everything you need to do in your head will overwhelm your brain's ability to process information, make decisions, and be creative. Whatever the source, capture the things you need to do, both personal and professional, in a system you trust.

"Prioritise prioritising_-do you regularly dedicate time to prioritising for the day, week, or month ahead before you accumulate more actions? Time is one of your most precious resources. You have to choose what you will and won't do or risk being driven by the actions that are shouting the loudest at the time.

"Automate or delegate-what tasks can you create an autopilot for? For example, paying bills by direct debit, getting a cleaner, or setting rules in your inbox to help your emails sort themselves. These actions then become something you only have to consciously interact with once in a while.

"Identify manageable actions-when you are feeling overwhelmed or something seems too challenging, identify the smallest possible next action that you feel you can do and do it. Then the next and so on. This helps create momentum.

"Email is not your to-do list-if the email contains an action then put the action in your system and don't rely on revisiting it in your inbox.

"Finally, treat this as a learning experience, be forgiving when things don't work, and celebrate the wins."

\section{Set boundaries}

Ellie Mein, medico-legal adviser at the Medical Defence Union, says, "Although time management can't increase the hours in the day or reduce your workload, it can help you feel more in control and reduce stress. It can also help you achieve your personal and professional goals and ensure you have enough time to effectively communicate with patients and colleagues and perform administrative tasks.

"With heavy workloads, effective time management is also important for clinician wellbeing and patient safety. A study by the University of Manchester and Keele University found that burnout was associated with an increase in the likelihood of unsafe care and unprofessional behaviour, such as not following treatment guidelines and poor quality communication. ${ }^{1}$ The researchers also found that patient satisfaction was likely to be lower when doctors were physically, emotionally, and mentally exhausted.

"Good time managers take a few minutes at the start of their day to prioritise tasks and consider how much time is needed to perform them. It can help to make a list, setting priorities according to urgency. You might think it's quicker to do everything yourself but appropriate delegation can help you to be more efficient.

"Although it can be easier said than done, try not to be distracted by non-urgent tasks and focus on your priorities. If a task seems 
overwhelming, break it down into smaller parts which are more achievable.

"Recognise that being a good team player doesn't equate to never saying no. Setting boundaries in a polite but firm way can help safeguard your time, allowing you to focus on the urgent tasks that only you can do."

\section{Plan and prioritise}

Sarah Christie, executive coach, says, "With increasing workloads and fewer resources, it's easy to fall into the habit of fire-fighting crises, while your to-do list gets longer.

"Accept that you will not get everything done on your to-do list each day, but make a list anyway, so that you can track what needs to be done.

"Rate your tasks in order of priority. Which ones must be done this week and cannot be delegated? Make sure these are ones that you rate as very important and highly urgent.

"Prepare a weekly schedule. Put in all your regular commitments such as meetings and clinics, and then look at it each day. Schedule in as many of your top priority tasks as you can.

"Be realistic about how long each task will take and allow some extra time because often things take longer than anticipated. Do not schedule back to back commitments in your day or you will slip straight back into feeling overwhelmed. Having gaps will give you the flexibility to move your planned tasks around, without causing you more stress if unexpected events occur.

"Most importantly of all, protect your planned schedule. Focus on your priorities and get them done.

"When your top priority tasks are complete you can then repeat the process with the next lot of tasks on your list-the ones that are also very important but not as urgent.

"Make this planning process a weekly habit and you will soon be back in control of your workload and your life."

Trevor Bibic will be delivering the seminar "Getting things done" at BMJ Live on 4-5 October 2019 at the Olympia Conference Centre in London. Register for free at: https://live.bmj.com

Panagioti M, Geraghty K, Johnson J, et al. Association between physician burnout and patient safety, professionalism, and patient satisfaction: a systematic review and meta-analysis. JAMA Intern Med 2018;178:1317-30. 10.1001/jamainternmed.2018.3713 30193239

Published by the BMJ Publishing Group Limited. For permission to use (where not already granted under a licence) please go to http://group.bmj.com/group/rights-licensing/ permissions 